\title{
A BIORREMEDIAÇÃO COMO TÉCNICA DE TRATAMENTO DE EFLUENTES CONTAMINADOS POR PETRÓLEO
}

\author{
Ariadne S. B. de Lima; UFERSA, Mossoró-RN. ariadnesbdelima@gmail.com \\ Criste J ones B. Simão; UnP, Mossoró-RN. criste@servindu.com.br. \\ Francisca J oseane de Sousa Silva; UnP, Mossoró-RN. fjoseanelegal@gmail.com \\ Júlia Rélene de Freitas Rodrigues; UERN, Mossoró-RN. juliarelene2@hotmail.com \\ Thiego Costa de Araújo; UnP, Mossoró-RN. thiegocaraujo@gmail.com
}

\section{resumo:}

Com o grande crescimento populacional e desenvolvimento tecnológico, a utilização dos recursos naturais está cada vez mais presente e constante, fazendo com que haja uma crescente utilização das reservas dos recursos e acarretando também preocupações, medidas e soluções no tocante ambiental, visto sua finitude e importância para a sobrevivência das extrações e utilizações. O foco deste trabalho está voltado à exploração petrolífera, atividade esta responsável por ser a fonte de energia fóssil mais utilizada no globo terrestre. Suas vantagens são vastas, porém seus impactos adversos, principalmente ao meio ambiente natural, são devastadores e de grande magnitude, causando perdas na fauna, flora e também á sociedade. Nessa linha de raciocínio, durante um desastre ambiental petrolífero, como exemplo um derramamento, são necessários métodos eficazes para combatê-lo; uma técnica que vem sendo estudada e utilizada é a de biorremediação de solos contaminados, a qual corresponde a um processo de tratamento que utiliza microorganismos que degradam e transformam compostos orgânicos em compostos menos complexos.

O presente trabalho trata-se de um estudo revisão bibliográfica, a partir do levantamento e seleção de materiais já publicados, entre artigos científicos, livros, web sites científicos como Scielo, Scorpus e Periódico Capes dos últimos 15 anos. O objetivo principal deste artigo consistiu em discutir e avaliar previamente sobre as técnicas de biorremediação, sua real importância e validade para com a problemática de derramamento do petróleo. As considerações finais após as análises dos documentos cientificos, mostram que esta técnica se mostra eficaz por se tratar de um processo de tratamento que utiliza microorganismos que degradam e transformam compostos orgânicos existentes nos solos contaminados, em compostos menos complexos e mais facilmente degradáveis, sendo uma alternativa para a recuperação de áreas contaminadas. É uma opção de tratamento viável, de baixo custo e que pode ser implantado em campo ou em sistemas fechados. Dessa forma, a biorremediação oferece algumas vantagens sobre outras técnicas de remedição, pois é ecologicamente correta, não altera o equilíbrio dos ecossistemas, visando somente a biodegradação dos compostos poluentes, reduzindo assim sua concentração ou toxicidade.

\footnotetext{
palavras-chave:

derramamento; Petróleo; biorremediação; meio ambiente; despoluição.
}

Espaço reservado para organização do congresso. 


\section{A exploração de petróleo e as técnicas para redução de impactos}

O mundo globalizado exige cada vez mais dos recursos naturais através da exploração das reservas florestais, das jazidas de petróleo, dos aquíferos, causando grandes transtornos ao meio ambiente. Com o aumento da utilização de combustíveis fosseis para geração de energia, aumenta a probabilidade e ocorrência do número de acidentes ambientes por derramamento de petróleo.

Embora seja de fundamental importância para a economia mundial, o petróleo e seus derivados são compostos complexos e altamente recalcitrantes causando impactos de proporção consideráveis aos ecossistemas (SOUZA, 2000).

A manifestação mais acentuada do fenômeno da poluição é a ocorrência de acidentes envolvendo petroleiros que provocam uma série de efeitos nocivos sob o solo e água, que impõem custos ao meio ambiente.

O ambiente marinho, por exemplo, devido sua vastidão sempre absorveu concentrações elevadas de substâncias estranhas (contaminantes). Estas substâncias incluem subprodutos de indústrias, águas contaminadas com pesticidas agrícolas, efluentes urbanos, óleos e misturas oleosas lançadas ao mar (NELSON, 2000).

Mesmo que o petróleo represente um grande negócio no mundo, envolve cerca de 683 bilhões de dólares por ano, é também uma das piores fontes de poluição, ao meio ambiente, e trazem prejuízos as atividades socioeconômicas nos territórios atingidos (SILVAMAR, 2002).

A fim de minimizar estes efeitos negativos da exploração do petróleo, o homem vem estudando medidas de amenizar esses impactos, sendo que na atualidade segundo cita Mayer apud Douglas (2000, p.05) damos destaque para as tecnologias ambientais como a remedição, pelo uso de dispersantes químicos ou de biossurfactantes e a biorremediação.

A biorremediação pode ser definida como um conjunto de tecnologias nas quais se utilizam microorganismos, ou seus produtos e processos, aplicadas a recuperação, ou remedição, de áreas contaminadas, tratamento de compostos orgânicos voláteis tóxicos ou efluentes que contenham resíduos que devem ser eliminados antes de entrar em contato com o ambiente. Em geral, utilizam-se microorganismos, plantas ou produtos biológicos, como enzimas e componentes celulares, com a finalidade de realizar a mineralização, a qual, possivelmente, resulta em gás carbônico e água como produtos finais (DIAS, 2000).

O conhecimento do processo de limpeza de petróleo por microorganismo, só vem aumentado a cada ano, onde as técnicas de biorremediação se mostram bastante efetivas para a limpeza de ambientes contaminados por hidrocarbonetos, devido a simplicidade da manutenção e baixo custo de execução (BUENO, 2008).

O maior conhecimento de população de bactérias e das condições que são favoráveis contribui para a elaboração de estratégias para reduzir o risco na exploração e agir de forma a detectar e antecipar os problemas na produção. Sendo assim, a opção pelo método a ser empregado vincula-se fortemente ao tipo de ecossistema impactando, levando-se em conta suas características e sensibilidade. (CANTAGALLO et al., 2002).

A capacidade de certos microrganismos em utilizar hidrocarbonetos como fonte de carbono foi apresentada pela primeira vez por Zobell em 1946, que verificou a presença destes em toda extensão no meio ambiente. 


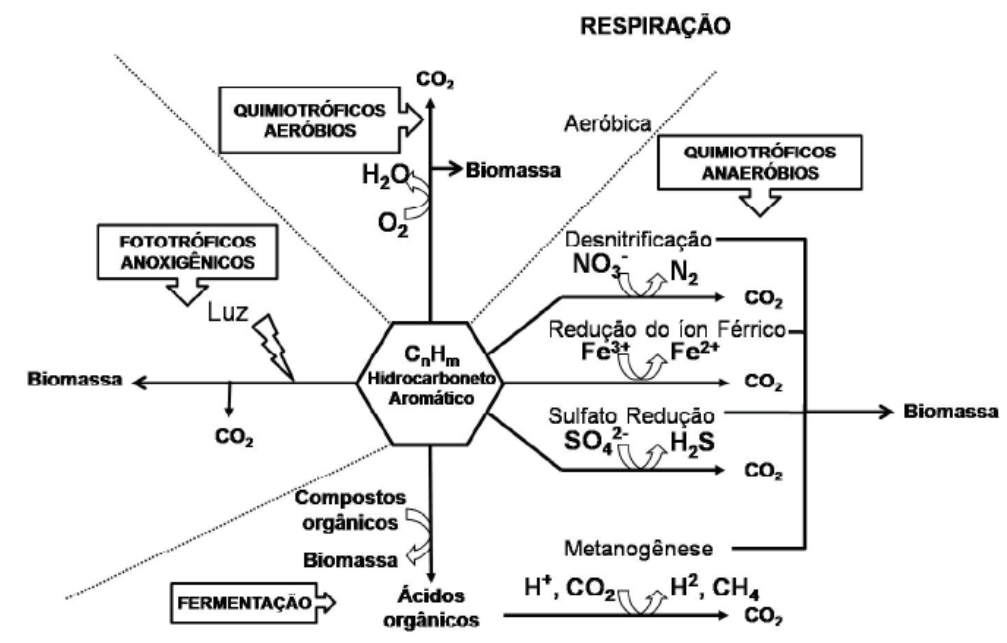

Gráfico 1 Utilização microbiana de compostos aromáticos por via aeróbia e anaeróbia, demonstrando os diferentes aceptores de elétrons na respiração. Figura adaptada de Díaz (2004) apus Tonini et al (2010).

A utilização dos hidrocarbonetos por estes, dependente da natureza química dos compostos existentes na mistura do petróleo e das condições ambientais.

Quando ecossistemas naturais são contaminados com hidrocarbonetos de petróleo, as comunidades microbiológicas presentes podem desenvolver estratégias de sobrevivência e até mesmo utilizar tais contaminantes como fonte de carbono, inclusive a partir da colaboração entre espécies diferentes e consórcios de microrganismos.

A Habilidade de microrganismos em utilizar hidrocarbonetos como fonte de energia é amplamente disseminada entre diferentes populações microbiológicas. Existem diversos gêneros e espécies de bactérias hidrocarbonoclásticas isoladas (bactérias que possuem a capacidade de quebrar cadeias de hidrocarbonetos), a maioria de ambientes aquáticos (BRITO, 2004).

Com base nesta característica, os microrganismos mais comumente utilizados em processos de biorremediação são as bactérias e fungos. Porém esta utilização deve ser realizada com cautela, pois as consequências podem ser mais danosas ao meio ambiente que o próprio petróleo.

Entre os fungos hidrocarbonoclásticos mais citados estão: Penicillium sp., Verticillium sp., Martieriella spp., Phoma spp., entre outros. Entre as algas e cianobactérias por sua vez, são citadas: Oscollatoria spp, Microcoleus AP., Anabaena spp. Agmenellum AP. (BRITO, 2004).

Segundo Tonini et al (2010), em seu trabalho sobre degradação e biorremediação de petróleo, as principais estruturas procariontes, a nível bacteriano, degradadoras de compostos hidrocarbonoclasticos são dos gêneros Acidovorans, Acinetobacter,Agrobacterium, Alcaligenes, Aeromonas, Arthrobacter,Beijemickia, Burkholderia, Bacillus, Comomonas,Corynebacterium, Cycloclasticus, Flavobacterium,Gordonia, Microbacterium, Moraxella, Mycobacterium,Micrococcus, Neptunomonas, Nocardia, Paracoccus,Pasteurella, Polaromonas, Pseudomonas, Ralstonia,Rhodococcus, Sphingomonas,Stenotrophomonas,

Segundo Lapinskas (1989) apud Mariano (2010) os vários tipos de petróleo, onde são utilizados diferentes microrganismos para que ocorra a biodegradação de forma menos impactantes, podem ser classificados como:

- Naftaleno: Acinetobacter calcoaceticus, alcaligenes denitri - cans, pseudômonas dentre outras. 
- Acenafteno: Beijenickia ps., P. uorescens, Buekholderia ceptia, Cycloclstius sp.,dentre outras.

- Fenantreno:pseromonas,A.feacalis,Micrococcussp, Polychromogenes dentre outras.

- Antraceno:Mycrobacteriumsp.,Paucimobiliss, Robococcus sp, dentre outras.

As bactérias pseudômonas, por exemplo, são utilizadas através dos biossurfactantes, o qual é produzido a partir de um processo de fermentação aeróbica dessas bactérias. Os biossurfactantes aumentam a interação superficial entre a água e o óleo, aceleram a degradação de vários óleos por microrganismos e promovendo biorremediação de água e solo (NITSCHKE; PASTORE, 2002).

Os biossurfactantes são moléculas produzidas pelas bactérias que reduzem a tensão superficial da área fronteiriça entre água e óleo nos reservatórios facilitando a mistura desses líquidos e a posterior degradação do petróleo. Estas por sua vez, produzem naturalmente o biossurfactantes quando são originárias de poços de petróleo, onde sua única maneira de sobrevivência é através do consumo das cadeias orgânicas do petróleo (ABALOS, 2001).

A temperatura tem notável efeito sobre a taxa de degradação microbiológica, atuando diretamente nas características físicas e na composição química e valorização na viscosidade do óleo; e no metabolismo bacteriano. De modo geral, as temperaturas mais baixas aumentam a viscosidade e reduzem a biodegradação do óleo. Por outro lado, o pH em faixas de 5-8, afetam principalmente a microbiota, inativando certas enzimas essenciais à sobrevivência das bactérias” (MARIANO, 2010).

Tanto nos reservatórios de petróleo como na água existem várias espécies de bactérias que se alimentam e degradam o óleo e ainda secretam biofilmes ${ }^{1}$. Com o inicio da produção submarina, os biofilmes, que também podem ser formados pela aglutinação das próprias bactérias, começam a se fixar em plásticos e metais. Essas estruturas de tamanhos micrométricos se acumulam e atingem espessuras de até 4mm (MARSAIOLI, 2008). O problema é que esses biofilmes prejudicam a exploração petrolífera porque eles grudam no interior das tubulações e corroem os dutos que são equipamentos de difícil limpeza (MARSAIOLI, 2008).

A maioria do óleo brasileiro tem baixo API por estar biodegradado, fazendo com que a sua produção, transporte, processamento e refino sejam bastante dispendiosos. Uma das hipóteses para a biodegradação é que isto se dê pela ação de bactérias aeróbicas. (PARENTE et al, 2004).

Existe uma grande discussão sobre o papel das bactérias aeróbicas na biodegradação do petróleo, pois diversos estudos demonstram que o oxigênio dissolvido na água de formação, é rapidamente consumido em reações de oxidação do meio mineral pela qual percola (FREDERICO, 2009), o que teria como resultado uma pequena influência das bactérias aeróbicas nos processo de biodegradação do petróleo, na maioria das situações onde ele é hoje encontrado, em especial nas águas profundas a ultraprofundas, onde se localizam os maiores campos produtores do Brasil. Diminuindo o oxigênio disponível no meio, bactérias aeróbicas ficaram impossibilitadas de sobreviver e assim degradarem o petróleo.

\section{Os processos de biorremediação: caracterizações e particularidades}

Cada processo de biorremedição é particular e quase sempre necessita de adequação e otimização específica para a aplicação em diferentes locais afetados, requerendo sempre uma análise integrada de parâmetros físicos, químicos e biológicos (BUENO, 2008).

Os fatores que poderão influenciar na biodegradação, serão fatores físicos e químicos no qual vão depender da composição da matriz do ambiente (pH, salidade, potencial oxirredução, etc), fatores extrínsicos (temperatura, umidade) e fatores relacionados ao poluente (estrutura química, presença de outros compostos, biodisponibilidade) (MELO e AZEVEDO, 2007).

${ }^{1}$ Estruturas moleculares usadas por eles para se proteger de agentes tóxicos e se fixar naturalmente em rochas e 
Os principais processos ou abordagens da biorremediação são através do uso de enzimas comerciais, uso de misturas de microrganismos (bioaumentação), uso de microrganismos imobilizados, DNA recombinante e remoção microbiológicas de metais. A implementação de um processo de biorremediação considera: avaliação da natureza do composto, caracterização da contaminação, planejamento do tipo de biorremediação e decisão por biorremediação in situ ou ex situ (OLIVEIRA, 2002).

Em princípio, requer-se uma remedição que seja adequada tanto à proteção da saúde humana quanto à do meio ambiente de um modo geral, levando-se em conta: as incertezas no que se refere à disposição do poluente no terreno; persistência, toxidez, mobilidade e tendência à bioacumulação das substâncias; riscos à saúde humana a curto e longo prazo; custos de manutenção em longo prazo; possibilidade de custos futuros de limpeza se a remedição não funcionar (VIDALLI, 2001).

Os microrganismos podem ser empregados para atacar contaminantes específicos da água e do solo, tais como no processo de degradação de hidrocarbonetos pelas. Um exemplo mais geral é a limpeza de derramamento do óleo pela adição dos fertilizantes de nitrato ou de sulfato para facilitar a decomposição do óleo pelas bactérias locais.

Muitas vezes um simples auxílio não é suficiente para a remedição por biodegradação natural. Em alguns casos são aplicadas verdadeiras técnicas de engenharia, que vão desde a modificação topográfica do local, até a introdução de novos microrganismos (organismos autóctones), assim como, o uso de biorreatores, e a adição de nutrientes. As técnicas que alocam grande quantidade de recursos tecnológicos aliadas a um planejamento meticuloso e extenso, são chamadas de biorremediação engenhada. A biorremediação engenhada, dependendo das circunstâncias, pode ser realizada in situ, e ex situ (MARTINS et al., 2003).

A introdução de microorganismos sejam eles OGMs ou não, a utilização de estratégia que favoreçam o aumento de populações microbianas especificas em um dado ambiente para fins de biorremediação requer, necessariamente, a adoção de praticas de monitoramento microbiológico voltadas para a detecção e/ou qualificação de microorganismos e/ou dos genes introduzidos no ambiente.

A mobilização dos metais é a passagem de um estado insolúvel inicial, correspondente a uma fase sólida, para um estado solúvel final em fase aquosa (Pérez, 2006). Os microorganismos podem mobilizar os metais através da lixiviação autotrófica e heterotrófica (Gadd, 2004). A imobilização é definida como a passagem de um estado solúvel inicial em fase aquosa para um insolúvel final em fase sólida (Pérez, 2006).

No caso de problemas causados pela contaminação devido à liberação de rejeitos industriais, várias técnicas já foram utilizadas, como por exemplo, a remedição através de processos químicos, a remedição feita através de microorganismos com relação menor agressão a todo ecossistema envolvido. Os processos microbiológicos de remedição dos metais, por exemplo, utilizando os métodos de mobilização e a imobilização apresentam um grande potencial biotecnológico.

\section{Processos off site versus on site}

O processo de biorremediação de áreas afetadas por hidrocarbonetos pode ser classificado em três tipos diferentes, de acordo com o local que vai ser tratado. Sendo o in situ o tratamento feito no local da contaminação; o ex situ ou off site a remoção do solo contaminado para posterior tratamento em outro local; e o on site onde o tratamento ocorre após escavação do solo (SELL, 2008).

A técnica in situ, geralmente, envolve o aumento da atividade microbiana local, por meio da alteração da área degradada, usando-se a adição de nutrientes, ajuste de ph, o controle da umidade e da aeração para proporcionar as condições ótimas de degradação biológica dos componentes tóxicos (BOOPATHY, 2000; MARTINS, 2003). 
O processo in situ ocorre no local onde acontece o confinamento usando barreiras de baixa permeabilidade: coberturas, barreiras verticais e barreiras horizontais (SELL, 2002).

O processo de remedição ex situ se passa através dos mecanismos, químicos, físicos, biológicos e térmicos. O químico ocorre a neutralização e extração do material por solvente. Físico, lavagem de solos, estabilização, solidificação e verificação. Biológico, biopilhas e biorreatores e o térmico, incineração e dessorão térmica (BOSCOV, 2000).

No processo ex situ o material (solo) contaminado é retirado e deslocado até a unidade de tratamento. Para este propósito, emprega-se a remoção do material contaminado, geralmente escavando o local. Se for na água, ocorre o bombeamento do material.

O processo de remediação in situ se passa através dos mecanismos, químico, físico, biológico e térmico. O químico ocorre a oxidação, redução dos materiais. Físico, lavagem, estabilização/solidificação, vitrificação, aspersão de ar abaixo do nível freático ( air sparging), extração de vapor do solo, eletrocinese. Biológico, atenuação natural monitorada, aspersão de ar acima do nível freático (biosparging). Térmico, injeção de vapor, aquecimento por radiofreqüência, vitrificação (BOSCOV. 2000).

Esse tipo de remediação é mais preferível, pois não envolve deslocamento de material contaminado, porém é preciso controlar o ambiente com equipamentos especializados para o tal processo ocorrer.

A opção pelo método a ser empregado vincula-se fortemente ao tipo de ecossistema impactado, levando-se em conta suas características e sensibilidade. Envolve também o tipo de óleo derramado e fatores técnicos, tais como acesso ao tipo de equipamento possível de ser utilizado, além de custo da operação (MILANELLI, 1994).

As estratégias de biorremediação mais conhecidas e estudadas incluem técnicas como a atenuação natural, bioventilação, landfarming, fitorremediação, além de técnicas auxiliares, como bioaumento e bioestímulo (SKIPPER, 1999; apoud BENTO et at., 2005).

\section{Considerações Finais}

A biorremediação é um processo de tratamento que utiliza microorganismos que degradam e transformam compostos orgânicos existentes nos solos contaminados, em compostos menos complexos e mais facilmente degradáveis, sendo uma alternativa para a recuperação de áreas contaminadas. É uma opção de tratamento viável, de baixo custo e que pode ser implantado em campo ou em sistemas fechados.

Existem varias técnicas para a recuperação de águas subterrâneas contaminadas. A escolha de qual técnica utilizar constitui um processo complexo de estudos de viabilidade técnicos econômica, envolvendo conceitos detalhados de como se constitui o local e qual o tipo de poluente.

De um modo geral, os métodos preferenciais de tratamento do conjunto água-solo são aqueles que reduzem permanentemente o volume, toxidez ou mobilidade das substâncias poluentes, como é o caso, por exemplo, da incineração. As alternativas menos desejáveis são usualmente as que envolvem transporte para outro local e disposição de substâncias perigosas sem tratamento.

Assim a biorremediação oferece algumas vantagens sobre outras técnicas de remedição, pois é ecologicamente correta, não altera o equilíbrio dos ecossistemas, visando somente a biodegradação dos compostos poluentes, reduzindo assim sua concentração ou toxicidade 


\title{
THE BIOREMEDIATION HOW TO WASTEWATER TREATMENT TECHNICAL CONTAMINATED BY OIL
}

\begin{abstract}
:
With the large population growth and technological development, the use of natural resources is increasingly present and constant, so that there is a growing use of reserves of resources and also causing concerns, measures and solutions in the environmental respect, as its finitude and importance to survive the extractions and uses. The focus of this work is focused on the oil exploration activity is responsible for being the fossil energy source most used on the globe. Its advantages are vast, but its adverse impacts, especially to the natural environment, are devastating and of great magnitude, causing losses in fauna, flora and also to society. This line of reasoning during an oil environmental disaster, such as a spill, effective methods are needed to combat it; a technique that has been studied and used is bioremediation of contaminated soils, which corresponds to a treatment process that uses microorganisms which degrade and convert organic compounds into less complex compounds. This paper deals is a literature review study, based on a survey and selection of material already published, including scientific articles, books, web sites like scientific Scielo, Scorpus and Capes Journal of the past 15 years. The aim of this article is to discuss and evaluate previously on bioremediation techniques, its real importance and validity towards the oil spill problem. The final consideration after the analysis of the scientific documents show that this technique proves to be effective because it is a treatment process that uses microorganisms which degrade and convert existing organic compounds in contaminated soil, in less complex compounds or easily degradable, one Alternatively for the recovery of contaminated areas. It is a viable treatment option, low cost and that can be deployed in the field or in closed systems. Thus, bioremediation offers some advantages over other remediation techniques because it is environmentally friendly, does not alter the equilibrium of ecosystems, targeting only the biodegradation of the polluting compounds, thereby reducing their concentration or toxicity.
\end{abstract}

\section{Keywords:}

spill; oil; bioremediation; environment; pollution.

\section{Referências bibliográficas}

ANTONINI, Sandra Regina Ceccato. Métodos de análises e monitoramento: Microbiológico em laboratório de destilaria. 2004.

BRITO, E M S, Degradação de óleo por bactérias isoladas dos sedimentos de manguezal da APA: Tese de Doutorado em geociências. Rio de Janeiro, Universidade Federal Fluminense. 2004.

BUENO, Silvia Messias. Bactérias produtoras de biossurfactantes: Isolamento, produção, caracterização e Comportamento num sistema modelo. 2008. 
CANDIDA, Rosana Marcedo et al. Biorremediação de solos impactados por óleo cru utilizando fungos filametosos. Disponível em: $<$ http://www.cetem.gov.br/publicacao/serie_anais_X_jic_2002/Victor.pdf $>$ Acesso em: 15 maio. 2010.

CANTAGALLO, Camila; CARLOS, João C. Milanelli; DIAS, Dimas Brito. Limpeza de ambientes costeiros brasileiros contaminados por petróleo: uma revisão. Disponível em: $<$ http://www.panamjas.org/pdf_artigos/PANAMJAS_2\%281\%29_1-12.pdf $>$. Acesso em: 12 maio. 2010.

CARAPETO, Cristine. Poluição pelo Petróleo. 2005, p.12.

CARVALHO, Denise. Processos de remediaçao de solos contaminados: Biodegradação de contaminantes ambientais. Disponível em: $<$ http://www.eq.ufrj.br/graduacao/aulas/biotecamb_denize/moduloIII.pdf $>$. Acesso em: 27 maio. 2010.

CETESB: Companhia de tecnologia de saneamento ambiental. Relação de áreas contaminadas, 2009. Disponível em: <http://www.cetesb.sp.gov.br/>. Acesso em: 17 de out. 2015.

COELHO, Diogo da Costa Identificação dos pontos críticos de contaminação e das técnicas de remediações utilizadas no caso de derramamento de óleo combustível A2, no município de hidrolândia/ Goiás. (2008). Disponível em: $<$ http://www.ucg.br/ucg/prope/cpgss/ArquivosUpload/36/file/IDENTIFICA\%C3\%87\%C3\%835O\%2 0DOS\%20PONTOS\%20CR\%C3\%8DTICOS\%20DE\%20CONTAMINA\%C3\%87\%C3\%830\%20E\% 20DAS\%20T\%C3\%89CNICAS\%20DE\%20REMEDIA\%C3\%87\%C3\%95ES\%20UTILIZADAS\%20 NO\%20CASO\%20DO\%20DERRAMAMENTO\%20DE\%20\%C3\%93LEO\%20COMBUST\%C3\%8D VEL\%20A2.pdf $>$. Acesso em: 25 de Maio de 2010.

CLAIRE,Christine Gaylarde; LOURDES, Maria de Bellinaso; PAULO, Gilson Manfio. Biorremediação: Aspectos biológicos e técnicos da biorremediação de xenobióticos. Biotecnologia, ciência \& Desenvolvimento. jan/jun. 2005. Disponível em

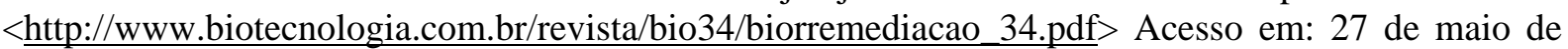
2010

CORRÊA, Oton Luiz; Petrobras: Noções sobre exploração, Perfuração, Produção e Microbiologia.Rio de Janeiro: Interciência, 2003.

CRUZ, Georgiana F. da; SANTOS NETO, E.V; MARSAIDE, A. J. Petrolium degradation by aerobic microbiota from the Pampo Sul oil Field: Orapinic Geochemistry: Campos Basin, Brasil. V. 39, p. 1.204-1.209, 2008.

LILIANA,Judithi Solórozono Lemos Et al. Técnicas de biorremediação de solos contaminados por hidrocarbonetos por hidrocarbonetos de petróleo. (2009).

LUIZ, Simone De Oliveira. Caracterização Da Resistência De Amostras De Acinetobacter Baumanniiisoladas No Hospital De Clínicas De Curitiba. 2006. Disponível em: < http://dspace.c3sl.ufpr.br/dspace/bitstream/handle/1884/4989/Disserta\%C3\%A7\%C3\%A30\%20Sim one A.\%20baumanni.pdf?sequence=1\&isAllowed $=\mathrm{y}>$. Acesso em: 16 de maio de 2010 .

MARIANO, A. P. Avaliação do potencial de biorremediação de solos e de águas subterrâneas contaminados com óleo diesel. 147 f. 2006. Tese (Doutorado em Geociências e Meio Ambiente) - Programa de Pós-Graduação em Geociências e Meio Ambiente, Universidade Estadual Paulista, Rio Claro, 2006. 
MAKIKO, K.; KAZUAKI, S.; SHUNJI, O.; SHIN, T.; AKIKO, M. Identification of alkane degrading bacteria in petroleum hydrocarbon-contaminated soil. Journal of Japan Society on Water Environment. V. 29, n. 1, p. 37-43, 2006.

MAYER, Douglas Bento Análise química da degradação dos Hidrocarbonetos de óleo Diesel no Estuário da Lagoa dos Patos- Rio Grande/RS. (2005). Disponível em: $<$ http://www.oceanfisquigeo.furg.br/dissertacoes/2005_Douglas.pdf> Acesso em: 12 maio.2010.

MENEZES, Everardo Albuquerque ET al. Atividade in vitro do Ertapenem e Meropenem contra Cepas de Acinetobacter baumannii isoladas, Ceará. 2003. Disponível em: $<$ http://www.scielo.br/scielo.php?pid=S0037-86822007000300021\&script=sci arttext $>$. Acesso em: 27 de Maio de 2010.

MELO, I. S; AZEVEDO, J.L de Eds. Microbiologia ambiental: Jaguaruína: Embrapa CNPMA, p.440. 1997.

MATTA, Renata dos Santos et al. Remediação de solos contaminado por petróleo em biopilhas ecala piloto. 2007.

MOTA, Débora. Bactérias tornam-se aliadas na limpeza de derramamentos de óleo: Bactérias comedoras de petróleo, Rio de Janeiro: Fape, agos. 2009

MURRAY, Patrick R.; ROSENTHAL, Ken S.; PFALLER, Michael A. Microbiologia Médica. 6. ed.Elservie:Rio de Janeiro. 2009.

NITSCHKE, M; PASTORE, G. M, Biossurfactantes: Propriedades e aplicações química nova. V. 25, n. 5, PP. 772-776. 2002

PRESTES, $M^{\mathrm{a}}$. Luci de Mesquita. A pesquisa e a construção do conhecimento cientifico: do planejamento aos textos, da escola à academia. 3. ed., 1. reimp. - São Paulo: Rêsple, 2008.

SHAH, Shah; A Historia do Petróleo: Entenda como e por que o petróleo dominou o mundo; Porto Alegre :LPM, 2007

SOUTO, Wagner. Fisiologia Bacteriana: Doenças Causadas por Bactérias.2008.

TONINI, Rita Maria Costa Wetler; REZENDE, Carlos Eduardo de; GRATIVOL, Adriana Daudt. Degradação e biorremediação de compostos do Petróleo por Bactérias: Uma Revisão. Oecol. Austr., [s.l.], v. 14, n. 04, p.1021-1035, 1 dez. 2010. Oecologia Australis. DOI: 10.4257/oeco.2010.1404.12.

TORTORA, Gerarde J; FUNK, Bedell R.; CASE, Cristine L. Microbiologia. $8^{\mathrm{a} e d . ~ A r t i m e d . ~ 2005, p .5-~}$ 6.

TUPI, Lucas Caldas Pereira; LILIANA, Judith Solórzano Lemos. Os fungos filamentosos, uma opção em estudo para a biorremediação II. Disponível em: < http://www.cetem.gov.br/publicacao/serie_anais_XI_jic_2003/18_Lucas_Tupi_JIC_2003.pdf $>$. Acesso em: 27 maio. 2010.

VIDALLI, M., 2001, “Bioremediation: an overview”, Pure Applied Chemistry. v. 73, pp. 1163-1172. 